\title{
Sensory Design of Foods for the Elderly
}

\author{
Gunnar Hall Karin Wendin \\ SIK - The Swedish Institute for Food and Biotechnology, Gothenburg, Sweden
}

\section{Key Words}

Experimental design - Texture-modified foods . Dysphagia · Sensory studies • Consumer studies . Focus group

\begin{abstract}
Background/Aims: Elderly persons with dysphagia need food that requires little or no chewing, that is easy to swallow and has attractive sensory characteristics. The aim was to investigate how ingredients varied according to experimental designs influence the perceived sensory, chewing and swallowing characteristics of two types of texture-modified model foods. Methods: Meat- and carrot-based, texturemodified model foods were produced. The following parameters were varied: particle size, fat content, starch and egg composition. The samples were studied using sensory analyses, focus group discussions and consumer studies. $\boldsymbol{R e}$ sults: The design parameters mainly had an impact on sensory texture attributes. The experts in the focus groups selected three products of each type which were regarded as being optimal for older persons. All the products contained a high proportion of egg yolk and a low amount of starch. Older consumers considered all the selected products to be easy to chew and swallow. The differences between older persons in nursing homes compared to those living in their own homes could be linked to health. Conclusions: Optimization of factors influencing food quality through the use of experimental designs in combination with sensory and consumer studies is required in order to meet the needs and demands of older people.

Copyright $\odot 2008$ S. Karger AG, Basel
\end{abstract}

\section{Background}

Eating normally is a pleasurable, social experience. From a physiological point of view eating is a complicated process that starts by taking food into the mouth. This is where the mechanical and chemical processing of the food begins before it is transferred via the esophagus to the stomach, where most of the digestion occurs [1]. The main purpose of chewing, which is the first step in the digestive process [2], is to reduce the particle size of the food, mix it with saliva and form a bolus appropriate for swallowing [3]. The coordination of the chewing process takes place by means of an exchange of information between various muscles and organs in the mouth and brain $[4,5]$. The multistage process of chewing includes cutting and grinding foods, mixing, transport movements and mid-sequence swallows [4]. Swallowing is defined as bolus flow from the lips to the stomach [6]. Chewing and mixing with saliva are the main events in the oral preparatory phase. In the oral propulsive phase the bolus is transported to the pharynx, where the reflexive pharyngeal swallow is triggered [6]. The pharyngeal phase of the swallowing involves a rapid sequence of overlapping events.

Chewing and swallowing in healthy individuals takes place without any problems. The time it takes before a bite of solid food or a sip of a drink is finally swallowed depends largely on the rheological properties of the food [3]. During chewing, various texture-related sensations are perceived. Furthermore, when chewing and swallowing take place normally, sensory stimuli that give rise to

\section{KARGER \\ Fax +4161306 1234 \\ E-Mail karger@karger.ch}

www.karger.com

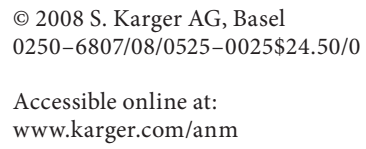

SIK - The Swedish Institute for Food and Biotechnology

Box 5401

SE-402 29 Gothenburg (Sweden)

Tel. +46 31335 5600, Fax +4631833 782, E-Mail karin.wendin@sik.se 
perception of taste and flavor are released $[7,8]$. Saliva plays an important role in the release of both taste and odor molecules.

There are as many as 30-40 different types of normal swallows. The type depends mainly on the characteristics of the food [6]. During aging, a lot of physiological changes that reduce chewing and swallowing ability may take place, ultimately leading to different degrees of dysphagia [9]. Impaired sensory perception [10] and impaired saliva production, i.e. xerostomia [11], are common. These changes influence many older persons' food intake by making the chewing and swallowing process more difficult and by reducing the enjoyment of eating. Older persons suffering from dysphagia usually eat smaller amounts of food and avoid foods with difficult-to-chew textures. Many also lose the enjoyment of eating meals together with others [12]. Dysphagia is a serious risk factor for anorexia in aging $[13,14]$.

One common treatment strategy of dysphagia is texture modification of foods $[15,16]$. However, like foods for persons with normal chewing ability, texture-modified foods should also be designed to give pleasurable meal experiences to those who eat them. It is a challenge for both food scientists and care-providers to design texture-modified foods with attractive sensory properties. This was the background to the present study, which was part of a larger collaborative project in which food companies, food scientists, nutritionists, speech therapists and videographic specialists participated. The aim was to investigate the influence of ingredients and particle size, varied according to an experimental design, on the perceived sensory texture characteristics as well as the chewing and swallowing characteristics of two types of texture-modified model foods, in order to find the optimum manufacturing conditions for such foods.

\section{Methods and Material}

\section{Material}

Two types of texture-modified model foods, one meat-based and one carrot-based, were produced by Findus AB (Bjuv, Sweden) according to experimental designs (tables 1,2$)$. The varied design parameters were: egg with a varied ratio of yolk/white (Källbergs Industri AB, Töreboda, Sweden); cold (Swely gel 7/90) or warm (Microlys 52) swelling starch (Lyckeby Culinar AB, Fjelkinge, Sweden); rapeseed oil (Karlshamn Oils and Fats, Karlshamn, Sweden), milled (purée form or 2-mm sieve) beef meat and carrots (supplied by Findus $\mathrm{AB}$ ). The remaining ingredients were broth (Lyckeby Culinar AB, Fjelkinge, Sweden) and water. All ingredients were mixed, poured into dishes and baked in an oven at $200^{\circ} \mathrm{C}$.
Table 1. Varied design parameters in meat-based products

\begin{tabular}{rllll}
\hline Sample & $\begin{array}{l}\text { Egg composition } \\
\text { (yolk/white ratio) }\end{array}$ & $\begin{array}{l}\text { Type of } \\
\text { starch }\end{array}$ & $\begin{array}{l}\text { Rapeseed } \\
\text { oil, } \%\end{array}$ & $\begin{array}{l}\text { Milling degree } \\
\text { of meat, mm }\end{array}$ \\
\hline 1 & $30 / 70$ & cold & 10 & purée \\
2 & $30 / 70$ & cold & 10 & 2 \\
3 & $30 / 70$ & cold & 20 & purée \\
4 & $30 / 70$ & cold & 20 & 2 \\
5 & $30 / 70$ & warm & 10 & purée \\
6 & $30 / 70$ & warm & 10 & 2 \\
7 & $30 / 70$ & warm & 20 & purée \\
8 & $30 / 70$ & warm & 20 & 2 \\
9 & $70 / 30$ & cold & 10 & purée \\
10 & $70 / 30$ & cold & 10 & 2 \\
11 & $70 / 30$ & cold & 20 & purée \\
12 & $70 / 30$ & cold & 20 & 2 \\
13 & $70 / 30$ & warm & 10 & purée \\
14 & $70 / 30$ & warm & 10 & 2 \\
15 & $70 / 30$ & warm & 20 & purée \\
16 & $70 / 30$ & warm & 20 & 2 \\
17 & $50 / 50$ & cold & 15 & 1 \\
18 & $50 / 50$ & warm & 15 & 1 \\
\hline
\end{tabular}

Table 2. Varied design parameters in carrot-based products

\begin{tabular}{lllll}
\hline Sample & $\begin{array}{l}\text { Egg composition } \\
\text { (yolk/white ratio) }\end{array}$ & $\begin{array}{l}\text { Microlys } \\
\text { starch, \% }\end{array}$ & $\begin{array}{l}\text { Rapeseed } \\
\text { oil, \% }\end{array}$ & $\begin{array}{l}\text { Milling degree } \\
\text { mm }\end{array}$ \\
\hline 1 & $30 / 70$ & 3 & 14 & purée \\
2 & $30 / 70$ & 3 & 14 & 2 \\
3 & $30 / 70$ & 3 & 20 & purée \\
4 & $30 / 70$ & 3 & 20 & 2 \\
5 & $30 / 70$ & 5 & 14 & purée \\
6 & $30 / 70$ & 5 & 14 & 2 \\
7 & $30 / 70$ & 5 & 20 & purée \\
8 & $30 / 70$ & 5 & 20 & 2 \\
9 & $70 / 30$ & 3 & 14 & purée \\
10 & $70 / 30$ & 3 & 14 & 2 \\
11 & $70 / 30$ & 3 & 20 & purée \\
12 & $70 / 30$ & 3 & 20 & 2 \\
13 & $70 / 30$ & 5 & 14 & purée \\
14 & $70 / 30$ & 5 & 14 & 2 \\
15 & $70 / 30$ & 5 & 20 & purée \\
16 & $70 / 30$ & 5 & 20 & 2 \\
17 & $50 / 50$ & 4 & 17 & 1 \\
\hline
\end{tabular}

The products were stored frozen $\left(-18^{\circ} \mathrm{C}\right)$ until analysis. They were then put into a fridge for thawing $6 \mathrm{~h}$ before use. The products were subsequently cut into cubes, approximately $30 \mathrm{~g}$ in weight. Meat products were heated to a serving temperature of $55^{\circ} \mathrm{C}$ and carrot products were served at ambient temperature. 


\section{Methods}

Descriptive sensory analyses were performed by a trained panel consisting of eight judges. The panel developed descriptive attributes during three separate training sessions for each type of product. The panel also agreed on intensity scales for the attributes. Intensities were rated on a continuous line scale, anchored with low intensity at $10 \%$ and high intensity at $90 \%$. A computerized system (FIZZ version 2.30C, Biosystemes, France) was used. The sensory analyses were performed during four sessions for each type of product.

Focus group discussions made up of experts working closely with older people suffering from dysphagia, e.g. dieticians, speech therapists, nurses and chefs, were performed in three Swedish cities, Malmö, Gothenburg and Umeå. The number of participants in each city varied between 6 and 10. The main purpose was to evaluate all meat and carrot products and to select the three samples of each type that were considered to be most suitable for older people suffering from dysphagia. The focus groups also discussed and agreed on important criteria for an optimum meal for this group of older people. The discussions were recorded on tape and then transcribed.

Older people, both those living on their own and those living in nursing homes, were invited to participate in a consumer study in order to judge acceptance of the selected texture-modified food products and also answer questions concerning their health status. The inclusion criteria were $\geq 70$ years, voluntary participation, linguistically and cognitively intact, with oral intake of food and the ability to eat meat and egg products. A total of 208 respondents participated in the study, 108 living on their own and 100 living in nursing homes [17]. A questionnaire consisting of three parts was used. The first part, 'Health status', included questions regarding height, body weight, weight changes during the last 6 months and oral medication. The second part, 'Chewing and swallowing status', included questions about chewing and swallowing function and oral status. In the last part, 'Acceptance and preference', the subjects were asked to test the selected meat- and carrot-based foods and to express their agreement with statements about the following: color and taste, ease of mastication, swallowing, eating and taking the product into the mouth; willingness to eat the product again. The items were rated on a 9-point Likerttype scale, where $1=$ do not agree at all and $9=$ agree fully.

Subjects living on their own carried out the study at SIK or in meeting rooms belonging to senior citizen societies or at home for those who were unable to come to SIK. The subjects filled in the forms independently. For subjects in nursing homes, information concerning health, chewing and swallowing status was obtained from the patient's medical records or verbally from the care person or nurse responsible. A dietician or speech therapist served as the interviewer and filled in the questionnaires.

Quantitative data were analyzed statistically using descriptive statistics, analysis of variance and multivariate statistics.

\section{Results}

Statistical analysis of the data from the sensory analysis showed that all the varied factors had significant impacts on the sensory characteristics of the texture-modi- fied products, mainly appearance and mouthfeel attributes. Higher oil content gave coarser and juicier meat products. A high proportion of yolk in the egg gave softer, coarser and fattier carrot products. A milling degree of $2 \mathrm{~mm}$ gave juicier and softer meat and carrot products than puréed products. The meat products were coarser with cold-swelling starch compared to those with warmswelling starch. A lower amount of starch resulted in carrot products with less detectable particles.

The focus groups considered carrot products 9,10 and 11 to be the most appropriate ones for older people with dysphagia and the most appropriate meat products were 9, 13 and 15 (tables 1,2). The selections were based on combinations of the following reasons: soft, smooth and creamy mouthfeel; not giving a greasy impression; easy to swallow; not sticky or grainy. The design characteristics of the selected carrot products were: egg with a high proportion of yolk; low amounts of starch; amount of oil and milling degree varied between the products. In the selected meat products, egg with a high proportion of egg yolk was also used. All products comprised puréed meat, while the amount of oil and the type of starch differed between the samples.

The focus groups considered the following criteria to be of greatest importance to the optimal meal experience: all components on the plate should be distinguishable from each other. The consistency of the food must be firmer for it to be easy to swallow. The meal should look appetizing and taste good. Food with intense taste and flavor is important to older people. A high nutritional value is also very important.

The number of participants in the consumer study was $208,66 \%$ women and $34 \%$ men, aged $70-99$ years. Subjects in nursing homes were on average older than subjects living on their own and predominantly women. BMI was $\leq 22$ in $20 \%$ of the whole sample and in $25 \%$ of subjects living in nursing homes. A weight loss of $\geq 0.5 \mathrm{~kg}$ during the last 6 months was reported by $14 \%$ of the men and $17 \%$ of the women. One-third of the women who reported weight loss $\geq 0.5 \mathrm{~kg}$ had a BMI $\leq 22$. Their prescription of drugs was higher compared to the women in the whole sample. The medication varied from 0 to 23 pharmaceuticals per day per subject. Only $20 \%$ of the subjects who reported difficulties when swallowing had a diagnosis of dysphagia [17].

Differences in acceptance and preference were found between subjects living on their own and subjects living in nursing homes. Many of the differences could be explained by differences in health and chewing and swallowing status. All three carrot products were perceived as 
being easy to masticate and swallow, regardless of the composition and the milling degree of the carrot. Those living in nursing homes perceived the products to be significantly easier to masticate compared to subjects living on their own. On the other hand, subjects living on their own expressed a higher degree of acceptance of the taste of the three products compared to subjects in nursing homes. All three meat products were perceived as being easy to masticate and swallow regardless of composition. However, subjects in nursing homes perceived the meat products to be significantly easier to masticate and swallow than subjects living on their own. Subjects in nursing homes were more willing to eat the three meat products again compared to subjects living on their own, which was probably due to the fact that some of the nursing homes did not always provide texture-modified food.

\section{Conclusion}

By varying the manufacturing of texture-modified meat- and carrot-based products according to the experimental design, large numbers of samples that varied significantly in sensory characteristics, mainly in texture attributes, were obtained. By allowing experts in focus groups to evaluate all the manufactured samples, limited numbers (three) of samples of each type, meat and carrot, respectively, that were considered to be the most appropriate for persons with chewing and swallowing difficulties, could be selected. A consumer study in which the selected samples of meat- and carrot-based products were tested by older respondents confirmed that all the selected samples were very easy to chew and swallow, both for respondents living on their own and for respondents living in nursing homes.

\section{Disclosure Statement}

The authors declare that no financial or other conflict of interest exists in relation to the content of the article.

\section{Acknowledgements}

This study was funded by VINNOVA (The Swedish Governmental Agency for Innovation Systems). The authors wish to thank Findus AB, Källbers Industri $A B$ and Lyckeby Culinar AB for providing ingredients and manufacturing samples. Thanks also to Margareta Bülow, University Hospital MAS; Elisabet Rothenberg and Julie Svantesson, Sahlgrenska University Hospital, and Susanne Ekman and Berit Albinsson at SIK for their assistance in the sensory and consumer studies. Thanks also to diploma students Sofia Hansson and Jennie Ottosson for their help with the focus group discussions.

\section{References}

1 Ferguson DB: Oral Bioscience. Edinburgh, Churchill-Livingstone, 1999.

-2 Gaviäo MBD, Engelen L, van der Bilt A: Chewing behaviour and salivary secretion. Eur J Oral Sci 2004;112:19-24.

-3 Hutchings JB, Lillford PJ: The perception of food texture: the philosophy of the breakdown path. J Texture Stud 1988;19:103-115.

4 Orchardson R, Cadden SW: Mastication; in Linden RWA (ed): The Scientific Basis of Eating. Basel, Karger, 1998, pp 76-121.

5 Bourne MC: Food Texture and Viscosity: Concept and Measurement. San Diego, Academic Press, 2002.

6 Logeman JA: The science of dysphagia; in Linden RWA (ed): The Scientific Basis of Eating. Basel, Karger, 1998, pp 223-238.

-7 Buettner A, Beer A, Hanning C, Settles M, Schieberle P: Physiological and analytical studies on flavour perception dynamics induced by the eating and swallowing process. Food Qual Pref 2002;13:497-504.

-8 Weel KGC, Boelrijk EM, Burger JJ, Verschueren M, Gruppen H, Voragen AGJ, Smit G: New device to simulate swallowing and in vivo aroma release in the throat from liquid and semisolid food systems. J Agric Food Chem 2004;52:6564-6571.

9 Smith Hammond C, Hudson Scharver C, Markley LW, Kinnally J, Cable M, Evanko L, Curtis D: Dysphagia Evaluation, Treatment and Recommendations; in Bales CW, Ritchie CS (eds): Handbook of Clinical Nutrition and Aging. Totowa, Humana Press, 2004, pp 547-568.

10 Schiffmann SS, Rogers M, Zervakis J: Loss of taste, smell and other senses with age: in Bales CW, Ritchie CS (eds): Handbook of Clinical Nutrition and Aging. Totowa, $\mathrm{Hu}-$ mana Press, 2004, pp 211-289.

11 Sreebny LM: Saliva in health and disease: an appraisal and update. Int Dental J 2000;50: 140-161.

12 Ekberg O, Hamdy S, Woisard V, WuttgeHanning A, Ortega P: Social and psychological burden of dysphagia: its impact on diagnosis and treatment. Dysphagia 2002:17: 139-146.

13 Hays NP, Roberts SB: The anorexia of ageing in humans. Physiol Behav 2006;88:257-266. $\checkmark 14$ Donini LM, Savina C, Cannella C: Eating habits and appetite control in the elderly: the anorexia of ageing. Int Psychogeriatr 2003; 15:73-87.

15 Bülow M: Therapeutic aspects of oral and pharyngeal swallowing dysfunction; thesis, Faculty of Medicine, Lund University, Malmö, 2003.

16 Atherton M, Bellis-Smith N, Cichero JAY, Suter M: Texture-modified foods and thickened fluids as used for individuals with dysphagia: Australian standardised labels and definitions. Nutr Diet 2007;64(suppl 2):S53S76.

17 Rothenberg E, Ekman S, Bülow M, Möller K, Svantesson J, Wendin K: Texture-modified meat and carrot products for elderly people with dysphagia - preference in relation to health and oral status. Scand J Food Nutr. Accepted for publication. 